\title{
O ENSINO DA ESCRITA VIA TEXTO NA FORMAÇÃO DOCENTE
}

\author{
TEACHING WRITING THROUGH TEXT IN PRACTICE TEACHERS' \\ FORMATION
}

Cleide Inês Wittke ${ }^{1}$

\begin{abstract}
RESUMO: Este artigo objetiva refletir sobre a produção escrita na formação inicial do docente, levando em conta atividades de ensino e de pesquisa. A partir de um aporte com interface entre duas teorias do texto: Linguística Textual (ADAM, 2011; KOCH, 2006; KOCH, ELIAS, 2010, 2016) e Interacionismo Sociodiscursivo (BRONCKART, 1999, 2008; MACHADO, 2005) e tomando o gênero textual como objeto de ensino (MARCUSCHI, 2008, 2010; SCHNEUWLY, DOLZ, 2009, 2010), realizamos este estudo com base em dois campos - i.e., ensino e pesquisa - vivenciados na nossa prática cotidiana como formadora de professores e pesquisadora em uma universidade do sul do Brasil. Com este estudo, concluímos que, embora o texto/gênero textual seja reconhecido como objeto de estudo, os futuros professores ainda encontram dificuldades em abordá-lo e produzi-lo sob uma perspectiva de interação, de construção de sentidos. Vemos o trabalho realizado através de projetos como uma das possibilidades para superar as dificuldades encontradas no ensino da escrita nas aulas de língua.
\end{abstract}

PALAVRAS-CHAVE: Formação Inicial; Ensino; Escrita; Teorias do Texto.

ABSTRACT: This article aims at reflecting about writing in practice teachers' formation, taking into account teaching and research activities. Having as theoretical underpinnings two text theories, Text Linguistics (ADAM, 2011; KOCH, 2006; KOCH, ELIAS, 2010, 2016) and Sociodiscursive Interactionism (BRONCKART,1999, 2008; MACHADO, 2005), and understanding text genre as a teaching object (MARCUSCHI, 2002, 2008; SCHNEUWLY, DOLZ, 2009, 2010),this study was conducted based on two fields of our everyday practice - i.e, teaching, as a teacher who supervises student-teachers, and researching, as a researcher in a university in the south of Brazil. Study findings suggest that, even though text/text genre has been acknowledged as a study object by practice teachers, they still face difficulties to approach it under an interactive, sense construal perspective. Within this context, we argue that writing production built through projects is an alternative to overcome the difficulties encountered when teaching writing in language classes.

KEYWORDS: Practice Teachers' Formation; Teaching; Writing; Text Theories.

\section{Considerações iniciais}

Por considerar a língua como um processo de interação verbal materializado por meio de textos, ou melhor, de gêneros textuais, defendemos que o ensino de português seja ministrado com base nesses instrumentos de comunicação, a partir das mais diversas situações enunciativas experimentadas em nosso cotidiano, seja lendo, falando e/ou

\footnotetext{
${ }^{1}$ Professora Associada na Universidade Federal de Pelotas na graduação e na pós-graduação. Doutora em Letras pela Pontifícia Universidade Católica do Rio Grande do Sul e pós-doutorado em Didática das Línguas na Universidade de Genebra.
} 
escrevendo. Nessas condições, se ensinar uma língua, no nosso caso, a língua portuguesa, é fazer o aluno dizer algo para outro alguém, em dada situação, com determinada intenção, o texto, sob uma abordagem de gênero textual (de sua intencionalidade e funcionalidade social, segundo MARCHUSCHI, 2010), mostra-se como instrumento adequado a essa prática docente. Vale lembrar que o fato de assumir a concepção de língua como interação verbal demanda mudanças na formação do futuro professor, pois esse profissional deverá ser preparado para ser capaz de selecionar os textos e de abordálos sob uma perspectiva social e interacionista da linguagem, tendo a ação de interação/comunicação como objetivo de seu trabalho.

Diante desse quadro, se o objetivo das aulas de línguas consiste em desenvolver a capacidade comunicativa, quer dizer, realizar exercícios de práticas de linguagem, de interação entre os sujeitos, o professor tem o compromisso de trazer diferentes textos à sala de aula, criando oportunidades para que o aluno estude, entenda e saiba fazer uso de variados gêneros textuais (ou de texto, como denominam BRONCKART, 1999, 2003; SCHNEUWLY, DOLZ, 2010), os quais circulam em nosso meio, nas mais diversas instâncias sociais (BAKHTIN, 1992).

A nosso ver, a distinção entre texto e gênero textual é tênue (e nos faz lembrar da comparação feita por Saussure entre as noções de língua e fala com os dois lados da folha de papel), ao ponto de, às vezes, os dois serem tomados como sinônimos, já que um depende do outro para que o projeto comunicativo se efetue. Sob uma perspectiva didática, quando nos referimos ao texto como modalidade textual, o vemos como estrutura, forma, considerando os elementos linguísticos, sintáticos, lexicais, textuais, semânticos e gramaticais que o constituem. Conforme Marcuschi (2010), atualmente existem cinco categorias e elas são denominadas por texto narrativo, descritivo, argumentativo, expositivo e injuntivo. Já os gêneros dizem respeito à intencionalidade e circularidade desses tipos de textos nas diferentes instâncias sociais, produzindo sentidos, conforme a intenção do autor. Podemos dizer que o gênero textual circula socialmente através de algum tipo de texto, dependendo da intenção do autor ao produzir seu dizer.

Também para Schneuwly e Dolz (2010), o gênero de texto é um (mega)instrumento, que possibilita a concretização da ação de linguagem (ato comunicativo). Seguindo tal abordagem, este artigo busca refletir sobre o ensino de língua, principalmente sobre o ensino da escrita sob a ótica da interação verbal e de seu 
efeito na formação inicial do professor, na tentativa de encontrar caminhos que possam aperfeiçoar a qualidade dessa formação e desse ensino na escola (MACHADO, LOUSADA, 2010; KOCH, ELIAS, 2010, 2016; WITTKE, 2015). Para tanto, enfatizamos acerca da importância de trabalhar com e no texto nas aulas de português, ao longo do ensino básico (GERALDI, 2006; MARCUSCHI, 2008), abordando tanto estratégias de leitura, de oralidade, quanto de escrita (com reescrita), escopo deste estudo. Vale dizer que, ao centrar nosso trabalho no processo do ensino de textos escritos, assim como Travaglia (2016, p. 87), também defendemos que a produção desses textos diz respeito a

\footnotetext{
[...] uma multiplicidade de fatos linguísticos e fatores, derivados da própria complexidade do texto, tais como: aspectos de coesão e de coerência, categorias de texto (tipos/subtipos, gêneros e espécies), processos argumentativos, conhecimento linguístico em geral, entre outros. A produção do texto depende diretamente do conhecimento de tais fatos, que, no caso do ensino/aprendizagem, não precisam necessariamente ser explicitados teoricamente para os alunos.
}

Mesmo que esta pesquisa possa parecer um simples relato de experiência, sem tirar o mérito de atividades dessa natureza, ela vai além, pois se trata de uma tentativa de colocar em prática, através da transposição didática (PETITJEAN, 1998; MACHADO, CRISTÓVÃO, 2006; WITTKE, 2007), as principais noções e conceitos específicos do ensino da escrita sob uma perspectiva da interação verbal (BAKHTIN, 1992; BRONCKART, 1999, 2003; KOCH, 2006; MARCUSCHI, 2008; KOCH, ELIAS, 2016). Em suma, entendemos que as experiências vivenciadas no campo do ensino e da pesquisa, conforme fizemos nesta investigação, podem e devem funcionar como dispositivo para que o professor formador de professores reflita sobre sua prática cotidiana, repensando acerca do seu papel social na sociedade contemporânea e também selecionando material para suas pesquisas (PERRENOUD, 1999; MACHADO, CRISTÓVÃO, 2006; MACHADO, LOUSADA, 2010; WITTKE, DOLZ, 2015).

Considerando que nossa investigação centra-se no ensino de língua e na formação docente, construímos uma reflexão a partir das experiências vivenciadas na universidade, tanto em ações de ensino quanto de pesquisa. Para contextualizar melhor, lembramos que este trabalho teve origem em uma proposta didática realizada a partir de leituras e discussões efetuadas com acadêmicos dos cursos de Letras de uma universidade do sul do país. As atividades foram realizadas em disciplinas voltadas ao ensino de Leitura e de 
produção de textos, ministradas no primeiro semestre dessas licenciaturas, e também com acadêmicos vinculados a um projeto de pesquisa intitulado: $O$ estudo da linguagem e da língua sob uma perspectiva da Interação Verbal. Esse projeto é coordenado pela autora deste artigo e conta com bolsistas de iniciação científica (Pibic/CNPq e Probic/Fapergs), mestrandos de Letras, professores universitários e do ensino básico.

Na sequência deste artigo, descrevemos a metodologia que norteou nosso estudo e também as atividades propostas nas disciplinas de leitura e produção textual, bem como no projeto de pesquisa. Feito isso, apresentamos os conceitos e as noções básicas que fundamentaram nossa abordagem do ensino da escrita via texto com interface entre a Linguística Textual (LT) e o Interacionismo Sociodiscursivo (ISD). Finalizamos com algumas conclusões a partir das experiências docentes vivenciadas e das reflexões sobre o processo de formação de professores.

\section{Metodologia: aporte teórico e transposição didática para elaborar um dispositivo de ensino voltado à produção escrita}

As atividades de ensino e de pesquisa, anteriormente mencionadas, foram organizadas com base em um aporte teórico construído pela interface entre a Linguística Textual (NEIS, 1981; KOCH, 2006; MARCUSCHI, 2008, 2010; ADAM, 2011; KOCH, ELIAS, 2010, 2016) e o Interacionismo Sociodiscursivo (BRONCKART, 1999, 2008; MACHADO, 2005; MACHADO, LOUSADA, 2010), cujo construto teórico serviu para fundamentar os exercícios voltados ao ensino da escrita (com foco na reescrita). Depois de aulas introdutórias sobre a perspectiva da linguagem/língua em uso (enquanto interação), seguimos os estudos das disciplinas e do projeto de pesquisa com leituras de textos previamente selecionados, identificando e definindo noções pertinentes a esse ensino, fazendo sua transposição didática. Foram definidos conceitos de linguagem/língua, gênero textual (ou de texto), sujeito, contexto, sentido, elementos de coesão e de coerência, pois são considerados fundamentais ao processo de produção escrita (DOLZ et al., 2010; SANTOS, TEIXEIRA, 2016).

O primeiro momento de construção do embasamento teórico foi realizado através de leituras e reflexões de textos que abordam sobre a língua (e seu ensino) como interação verbal, com definições de texto e de gênero textual; $(\mathrm{KOCH}, 1992 ; \mathrm{KOCH}$, TRAVAGLIA， 2001; KOCH， ELIAS， 2010， 2016; MARCUSCHI， 2010; 
SCHNEUWLY, DOLZ, 2010; ADAM, 2011); do processo de escrita e de reescrita e suas implicações no ensino de línguas (GERALDI, 2006; DOLZ et al., 2010). Nessa etapa da formação docente, para consolidar a transposição didática das teorias adotadas (MACHADO, LOUSADA, 2010), foram dadas orientações e feitas sugestões de como produzir e também corrigir textos dos alunos, nas aulas de português, em suas atuações futuras, na escola.

Construído o aporte teórico, foi dada sequência à formação docente tanto nas disciplinas supracitadas quanto no projeto de pesquisa, buscando aplicar a teoria em atividades práticas voltadas ao ensino da escrita. No caso específico da pesquisa, para a realização dos exercícios práticos, os estudantes pesquisadores foram orientados a adentrarem no ambiente escolar, com a finalidade de observar aulas e entrevistar professores e alunos, para, na sequência, elaborar e aplicar oficinas de escrita em turmas do ensino básico.

No que tange às disciplinas de leitura e produção de textos, a aplicação foi realizada por meio de exercícios práticos de produção textual, com foco na reescrita, apoiando-se em planilhas, grades, bilhetes, ora menos ora mais complexos (GONÇALVES, BAZARIM, 2009; SANTOS, TEIXEIRA, 2016). Nesse momento da formação inicial, foi dada atenção para que os exercícios práticos fossem abordados sob uma perspectiva dialógica da língua (BAKHTIN, 1992), buscando conscientizar o futuro professor acerca da complexidade desse processo de interação, enfatizando sua importância, com estímulo à prática da reescrita (WITTKE, 2012).

As tarefas de escrita propostas nas duas turmas de leitura e produção de textos (Português/Inglês; Português/Alemão) resumiram-se em produções orientadas de resumos e também de artigos de opinião. No primeiro exercício prático, os futuros professores elaboraram resumos de capítulos dos textos lidos durante o embasamento teórico, em especial, do livro Produção escrita e dificuldades de aprendizagem, de Dolz et al. (2010).

Os textos produzidos foram trocados entre os acadêmicos de suas respectivas turmas e por eles revisados; nesse primeiro momento, sem o auxílio de planilhas, de grades ou de outro instrumento de apoio. Os textos produzidos pelos acadêmicos, tanto na primeira quanto na segunda versão, depois de serem reescritos por seus respectivos autores, não foram lidos pela professora formadora (da disciplina de referência). Dando sequência ao dispositivo didático em curso, os licenciandos produziram artigos de 
opinião. Essa atividade foi realizada em dois momentos distintos. Na primeira proposta, depois de ler e discutir sobre o papel social do professor de línguas, os acadêmicos produziram um artigo fora da sala de aula, discorrendo sobre o tema. Após, na aula seguinte, os textos foram trocados e cada colega revisou um deles, com base em uma planilha simples, observando: tema, estrutura e elementos linguísticos, gramaticais e semânticos.

A segunda versão do artigo de opinião foi lida e avaliada pela professora formadora, a partir da mesma planilha simplificada já conhecida e manuseada pelos estudantes. Na sequência, foi proposta uma segunda atividade de escrita, novamente de um artigo de opinião, mas sobre outra temática, agora, realizada em aula e valendo nota. Os licenciandos sabiam que o assunto era o processo de escrita e seu ensino e foram orientados a lerem sobre esse tema, preparando-se para escrever um artigo de opinião a um jornal local da cidade. Os textos produzidos em aula foram lidos e avaliados pela professora formadora, a partir de uma planilha mais desenvolvida e com itens bem especificados, retirada de um texto de Santos e Teixeira (2016), cujo capítulo, e também a planilha, foram lidos e discutidos em aula.

Após ler a segunda produção de um artigo de opinião, a professora formadora selecionou fragmentos dos textos (um ou dois parágrafos) os quais, em conjunto, foram lidos, comentados e reformulados, conforme necessidade apontada e justificada pelos futuros professores. Para finalizar a atividade, um tex to completo foi analisado e reescrito pela turma, em grande grupo. Na sequência, eles selecionaram um dos textos de cada turma para serem publicados em um jornal local.

Já quanto à atividade prática de escrita proposta no projeto de pesquisa, que ainda está em andamento, inicialmente, cada pesquisador produziu e apresentou um subprojeto, ligado ao projeto guarda-chuva, e também elaborou questões para entrevistar professores e alunos das escolas onde vão aplicar suas propostas de pesquisas. Na continuidade do estudo, vão escrever relatórios sobre as aulas observadas nas escolas-alvo e elaborar proposta com atividades de escrita para as oficinas que serão realizadas em 2018, nas instituições de ensino parceiras do projeto. Durante esse período, os pesquisadores e bolsistas produziram textos para apresentar e publicar em eventos locais e regionais. Acreditamos que a realização de atividades dessa natureza vão preparar os futuros professores a se tornarem profissionais conscientes de seu papel de educadores, além de 
despertar a necessidade de pesquisar e de refletir sobre os efeitos de sua prática docente cotidiana (NÓVOA, 2002; WITTKE, DOLZ, 2015).

\section{Fundamentação teórica: o duplo estatuto na formação docente}

Como já dissemos, este trabalho foi produzido a partir de experiências vivenciadas na formação docente, no contexto universitário. Norteamos o embasamento pelas teorias da LT e do ISD, assumindo dois eixos: ora direcionado ao objeto de ensino a ser trabalhado nas aulas de língua, o que Schneuwly et al. (2012) denominam como objeto a ensinar, ora a questões específicas à formação docente, denominada pelos autores como objeto para ensinar, no qual o domínio da transposição didática é ainda mais relevante. Considerando que se trata de um processo de formação de professores, mesmo que sejam acadêmicos do primeiro semestre do Curso, entendemos ser pertinente abordar o ensino da escrita na escola sob duas perspectivas: do saber a ensinar e do saber para ensinar, já que ambos os conhecimentos e domínios são essenciais à formação de um profissional competente (MACHADO, LOUSADA, 2010; WITTKE, SCHNEUWLY, 2016).

Tomando como base os estudos de Bronckart (1999, 2008) sobre o agir profissional, definimos a prática docente como uma ação social que está diretamente ligada à realidade de cada sociedade, portanto, faz-se necessário que o professor entenda e saiba lidar com as mudanças sociais de cada época, levando em conta as demandas do meio no qual está inserido. Nessas condições, é preciso definir e especificar quais são as especificidades dos saberes a ensinar e do saber-fazer (para ensinar), diferentes domínios que o (futuro) docente precisa conhecer e dominar para construir um ensino e uma aprendizagem de qualidade. Seguindo essa perspectiva, Schneuwly et al. (2005), Cordeiro e Schneuwly (2007) explicitam que, além de dominar os saberes a ensinar, ou seja, os conteúdos oficialmente reconhecidos pelas instituições de ensino, que constituem os conteúdos programáticos e próprios das disciplinas de referência, o docente deve ter boa formação no que tange aos saberes para ensinar, isto é, sobre as técnicas, os domínios e os exercícios que desenvolvem a capacidade de ensinar, referentes às práticas didáticopedagógicas do saber-fazer (do savoir-faire, como diz PETITJEAN, 1998).

Os estudiosos da linguagem concordam que o professor deve ter uma formação sólida e consistente dos conteúdos (os objetos de ensino) que serão trabalhados em aula 
(geralmente abordados nas disciplinas de referência), mas também é necessária uma formação plena e consistente acerca do modo como esse saber será selecionado, programado, apresentado, trabalhado e avaliado no decorrer das aulas e também no curso dos anos (sua progressão), cumprindo os currículos pré-estabelecidos socialmente e oficialmente reconhecidos (SCHNEUWLY, DOLZ, 2010; SCHNEUWLY, 2014).

A partir de suas pesquisas voltadas à formação docente, Schneuwly et al. (2012) e Cordeiro et al. (2013) explicam que a profissão de professor é a única que possui duplo estatuto na sua formação: um voltado ao saber a ser ensinado (domínio e conhecimento dos conteúdos próprios das disciplinas de língua e literatura) e outro direcionado ao saber para ensinar (domínio e conhecimento sobre técnicas e modos de ensinar os conteúdos em questão, englobando as disciplinas de Psicologia, Didática, Pedagogia e Transposição Didática). Quanto à questão do duplo estatuto da formação docente e do caráter social do ensino de língua, cabe definir quais são os saberes essenciais a serem trabalhados na aula de português, no ensino básico. A partir do princípio de que o texto, e de modo mais amplo o gênero textual, é assumido como objeto de estudo nas aulas de língua materna, defendemos que esse ensino seja realizado sob uma abordagem dialógica e sociointeracionista, tendo o processo de interação verbal, ou melhor, a construção de sentidos como meta a ser atingida.

Retomando, então, o primeiro eixo descrito no início desta seção, ou seja, aquele voltado ao objeto de ensino a ser trabalhado nas aulas de línguas, e também considerando que o texto e o gênero textual (ou de texto) são elencados como objeto de ensino das aulas de português, cabe apresentar as noções que fundamentam nossas atividades de escrita no âmbito da atividade de ensino e de pesquisa, campos de estudo desta reflexão. Como já discorremos em um artigo sobre a prática da escrita, publicado em 2012, definimos o texto como uma materialidade linguística de variada extensão que constitui um todo organizado de sentido, quer dizer, é coerente e adequado à comunicação (tanto oral quanto escrita) à qual se propõe, em determinada situação social.

Nessa perspectiva, assim como Marcuschi (2010, p. 24), definimos texto como "uma identidade concreta realizada materialmente e corporificada em algum gênero textual". Também considerando o texto como uma produção verbal de caráter linguístico, social e cultural, Koch e Elias (2016) defendem que: 
[...] o texto é um objeto complexo que envolve não apenas operações linguísticas como também cognitivas, sociais e interacionais. Isso quer dizer que na produção e compreensão de um texto não basta o conhecimento da língua, é preciso também considerar conhecimentos de mundo, da cultura em que vivemos, das formas de interagir em sociedade (KOCH, ELIAS, 2016, p. $15)$.

Como vemos, o domínio das práticas de linguagem, principalmente de compreensão e de produção de um texto, seja ele oral ou escrito, exige variados conhecimentos que ultrapassam as operações linguísticas e cognitivas, levando em conta também elementos textuais, contextuais, sociais, culturais e discursivos. Ao comparar o texto com um iceberg, Koch e Elias (2016) defendem que quanto maior for o conhecimento sobre os diferentes elementos que constituem a língua, mais chances o leitor ou ouvinte terá para compreender os sentidos veiculados em um texto, nas mais diversas situações de uso. Para as estudiosas da linguagem, o texto

\footnotetext{
apresenta uma pequena parte na superfície da água (os elementos linguísticos que compõem sua materialidade) e uma imensa superfície subjacente (todos os conhecimentos que necessitam ser ativados para a produção de um sentido). Quanto maior a bagagem de conhecimentos de que o leitor/ouvinte dispuser, mais facilidade ele terá de chegar às profundezas do iceberg, para delas extrair os elementos que lhe vão facultar a produção de um sentido adequado para o texto que ouve ou lê (KOCH, ELIAS, 2016, p. 34).
}

Sob tais condições de uso, o texto, ao circular socialmente, em uma enorme gama de gêneros textuais, pode ser desde um enunciado como: Polícia! Atenção! Mãos ao alto! ou uma crônica, uma propaganda, um editorial, um atestado, uma receita culinária, um resumo, um artigo acadêmico, uma tese. É nesse sentido que Dolz e Abouzaïd (2015, online) definem os gêneros como "instrumentos semióticos, que cristalizam as significações associadas às práticas sociais cuja associação permite a interiorização de experiências culturais historicamente sedimentadas". Dolz-Mestre et al. (2001) caracterizam o gênero de texto como "o que é dizível, sob quais estruturas textuais, com quais meios lingüísticos” (p. 12).

Desenvolvendo pesquisas sobre o ensino de gêneros orais e escritos na escola desde os anos de 1980, Schneuwly e Dolz (2010), juntamente com outros didaticistas do grupo de Genebra, vêm desenvolvendo projetos didáticos de gêneros e defendem a necessidade de realizar atividades que desenvolvam as práticas de linguagem por meio de gêneros de texto. Os resultados obtidos com suas pesquisas mostram que esse ensino tem 
sido ainda mais eficaz quando realizado através de sequências didáticas (SD). Segundo os autores, a SD é "um conjunto de atividades escolares organizadas, de maneira sistemática, em torno de um gênero textual oral ou escrito" (DOLZ et al., 2010, p. 82). Ainda segundo esses estudiosos, "uma sequência didática tem, precisamente, a finalidade de ajudar o aluno a dominar melhor um gênero de texto, permitindo-lhe, assim, escrever ou falar de uma maneira mais adequada numa dada situação de comunicação" (p. 83). Por meio de SDs, o professor consegue propor diferentes atividades de observação, manipulação e análise de unidades linguísticas e semânticas, dos inúmeros gêneros que circulam em nossa sociedade. Dentre outras possibilidades, esse trabalho pode centrar-se nas:

marcas de organização características de um gênero, nas unidades que permitem designar uma mesma realidade ao longo de um texto, nos elementos de responsabilidade enunciativa e de modalização dos enunciados, no emprego de tempos verbais, na maneira como são utilizados e inseridos os discursos indiretos (DOLZ et al., 2010, p. 96).

Já no que tange ao segundo eixo, ou seja, ao saber voltado ao desenvolvimento de conhecimentos próprios para a ação de ensinar (didática, transposição didática, dispositivo didático e pedagógico), esse remete a domínios que o professor dispõe para realizar seu trabalho em aula, ou seja, são aqueles saberes específicos para efetuar a prática docente. Consiste no conhecimento da transposição didática, no domínio de como ela funciona e também de como colocá-la em prática (PETITJEAN, 1998; SCHNEUWLY, DOLZ, 2009; MACHADO, LOUSADA, 2010).

Resumidamente, são os conhecimentos que dizem respeito à didática, à realização concreta do trabalho em aula, são os diferentes gestos do professor, mas também saberes sobre Sociologia da Educação, Psicologia e História da Educação (SCHNEUWLY, 2014). Os saberes para ensinar são aqueles que permitem ao professor se situar como profissional da educação, em relação à ação de seu ensino, tanto no que diz respeito à preparação das aulas, à escolha do(s) texto(s), dos dispositivos didáticos e pedagógicos, das atividades e dos exercícios a serem preparados (ou aplicados, no caso do livro didático), quanto à sua ação em sala de aula (SCHNEUWLY, DOLZ, 2009, 2010).

Os saberes para ensinar são bastante amplos, principalmente os das Ciências da Educação, mas também são conhecimentos gerais das Didáticas (da leitura, da oralidade e da escrita), tais como gestos didáticos e processo de sedimentação. Conforme entrevista 
concedida por Dolz à autora deste artigo (WITTKE, DOLZ, 2015), as bases, os fundamentos linguísticos em Ciências da Educação e em Psicologia não são suficientes para a didática das línguas, tanto da leitura, da oralidade quanto da escrita. O ensino e a aprendizagem de línguas, o trabalho concreto (ou seja, o exercício do docente em sala de aula) demanda uma operacionalização dos conceitos, os quais podem servir para o professor nas suas práticas cotidianas, bem como para os professores formadores, em suas pesquisas, conforme realidade concretizada neste artigo.

Por tudo que já foi exposto, reiteramos a necessidade de o professor ter consciência e também domínio das engrenagens que constituem o processo de ensino e de aprendizagem para que consiga lidar com as dificuldades apresentadas pelos alunos, quando estiver em sala de aula. Esses são os saberes que mobilizam o modo de agir do docente, são os saberes para ensinar. Ainda que não sejam conhecimentos voltados diretamente aos objetos a ensinar, eles são essenciais para que o professor se torne um profissional competente e seguro na e da sua atuação.

Os saberes para o ensino vistos como fundamentais na formação docente são os quatro gestos profissionais a serem realizados pelo professor (SCHNEUWLY et al., 2005). O mestre deve (i) planificar o trabalho da aula (relação do professor com o saber); (ii) criar situações de ensino pertinentes (criar dispositivos didáticos, de ensino); (iii) utilizar a memória do que já foi ensinado antes (já que o professor é tido como o guardião da memória didática da turma); (iiii) regular o ensino (via avaliação como diagnóstico da aprendizagem), fazendo intervenções quando o aluno encontra dificuldades e também com o objetivo de questioná-lo, motivando nova aprendizagem.

\section{Considerações finais}

Levando em conta as ações experimentadas enquanto formadora de professores de língua portuguesa em uma universidade federal do sul do país (bem como a experiência de 15 anos como professora de língua materna e estrangeira no ensino básico) e o diálogo com colegas formadores de todo o Brasil, e também do exterior, através de eventos e de publicações, podemos dizer que o sistema de formação docente brasileiro (em muitos cursos de Letras) deixa a desejar e precisa urgentemente de mudanças. Especialmente no que diz respeito à seleção dos objetos que serão ensinados, mas também quanto ao modo de abordá-los, incluindo procedimentos didáticos, pedagógicos e de transposição didática. 
A partir de uma perspectiva dialógica, social e interacional da linguagem, defendemos que a função do professor de língua é a de ensinar o aluno a desenvolver e aperfeiçoar sua capacidade de usar a linguagem, por meio de textos/gêneros textuais que circulam em nossa sociedade contemporânea. Assim, a principal meta desse ensino é a de criar condições para que o estudante se comunique com clareza e fluência, desenvolvendo tanto sua capacidade de ler, compreender e interpretar textos, nos mais variados temas e gêneros, quanto sua habilidade de se expressar falando e escrevendo nas mais diversas situações enunciativas vivenciadas no dia a dia.

Ao caracterizar as aulas de línguas, Schneuwly e Dolz (2010, p. 69) dizem "tratase de colocar os alunos em situações de comunicação que sejam o mais próximo possível de verdadeiras situações de comunicação, que tenham um sentido para eles, a fim de melhor dominá-las como realmente são, ao mesmo tempo sabendo, o tempo todo, que os objetivos visados são (também) outros”. Isso implica que, mesmo que o professor traga textos autênticos para a sala de aula, simulando situações comunicativas como as vivenciadas no cotidiano, ao serem inseridos na escola, esses instrumentos assumem novo objetivo, pois, além de comunicar, passam a funcionar como objeto de ensino (PETITJEAN, 1998).

Em resumo, o que o presente trabalho procurou mostrar, através de atividades práticas e cotidianas de ensino e de pesquisa, realizadas tanto pelo professor formador de professores quanto pelos acadêmicos, é que a tão esperada mudança nesse ensino (com ênfase na prática da leitura e da produção escrita de diversos gêneros textuais que circulam em nosso meio) deve ter início na formação inicial dos futuros professores e, se possível, logo nos primeiros semestres dos cursos de licenciaturas em Letras. Também entendemos que a produtividade e a qualidade do trabalho docente vão depender diretamente da formação que as licenciaturas, pelo trabalho e engajamento dos professores formadores, oportunizam aos acadêmicos ao longo dos quatro (ou mais) anos de estudo, organizando e ofertando não só atividades de ensino, mas também projetos de pesquisa e de extensão.

A experiência no campo do ensino e da pesquisa, envolvendo futuros professores, professores formadores e do ensino básico, mostrou que, de modo geral, o licenciando tenta conceber o texto/gênero textual como objeto de estudo, no entanto, apresenta dificuldades em trabalhar o ensino da leitura, da oralidade e da escrita sob uma 
perspectiva de interação verbal, como processo comunicativo que constrói sentidos. Certamente que esse resultado não foi obtido apenas pela experiência com o ensino de acadêmicos do primeiro semestre, uma vez que eles ainda têm muito presente a experiência de alunos do ensino médio e não de futuros professores de línguas, mas é nesse momento que começamos a construir as bases desse profissional.

Tomamos como referência os relatos feitos pelos licenciandos, sobre o processo de letramento vivenciado ao longo de sua escolarização. Além disso, as entrevistas e as observações de aulas realizadas pelos pesquisadores do grupo de pesquisa, em diferentes escolas do ensino básico, tendo o trabalho com a escrita como foco, também corroboraram para que chegássemos a essa conclusão. Vale lembrar que a atividade realizada nas disciplinas de leitura e produção de textos com os acadêmicos foi um trabalho pontual e as pesquisas de nosso projeto ainda estão em andamento, mas, mesmo assim, foi possível constatar que a realização de projetos, sejam eles de ensino, de pesquisa ou de extensão, direta ou indiretamente ligados com as disciplinas de referência, voltados ao saber a ensinar e/ou para ensinar, é um dos caminhos promissores para desenvolver as práticas de linguagem - de leitura, de oralidade e de escrita - com os futuros professores de língua.

Nesse contexto, se nossa meta é formar um professor de línguas consciente de seu papel e engajado no compromisso de ensinar o aluno a ler e a escrever, principalmente, a saber pensar e agir (verbalmente) diante das situações sociais, precisamos começar esse movimento didático-pedagógico já nas atividades iniciais da formação dos futuros professores. Esse é o principal objetivo desta reflexão: mostrar a viabilidade de trabalhar as práticas de linguagem por meio de textos/gêneros textuais e também atividades de pesquisa no primeiro semestre das licenciaturas de Letras. Esta é uma dentre as inúmeras atividades possíveis e que vêm sendo realizadas nas universidades brasileiras. Cabe a nós, professores formadores, socializar nossas experiências profissionais com nossos pares, pois, assim, as práticas docentes e também as investigações nas pesquisas podem se expandir e motivar um número maior de profissionais na área. 


\section{REFERÊNCIAS}

ADAM, J-M. A Linguística Textual: introdução à análise textual dos discursos. 2. ed. São Paulo: Cortez, 2011.

BAKHTIN, M. Estética da criação verbal. Traduzido por Maria Ermantina Galvão G. Pereira. Martins Fontes, 1997.

BRONCKART, J-P. Atividade de linguagem, textos e discursos. São Paulo: PUC-SP, 1999.

Gêneros textuais, tipos de discursos e operações psicolinguísticas. Rev. Est. Ling., Belo Horizonte, v.11, n.1, p.49-69, jan./jun. 2003.

O agir nos discursos: das concepções teóricas às concepções dos trabalhadores.

São Paulo: Mercado de Letras, 2008.

CORDEIRO, G.S.; SCHNEUWLY, B. Les constructions de l'objet enseigné et les organisateurs du travail enseignant. Recherche et Formation, n. 96, p. 67-79, 2007.

CORDEIRO, G. S. et al. De la fonction didactique des justifications dans la construction des savoirs en lecture/compréhension et en sciences de la nature au cycle 1: une réflexion sur les cadres conceptuels des recherché didactiques. In: J.-L. Dorier, F. Leutenegger e B. Schnewuly. Didactique en construction, constructions des didactiques. Bruxelles: De Boeck, 2013, p. 255-279.

DOLZ, J. et al. Produção escrita e dificuldades de aprendizagem. São Paulo: Mercado de Letras, 2010.

DOLZ et al. Seqüências didáticas para o oral e a escrita: apresentação de um procedimento. In: SCHNEUWLY, B.; DOLZ, J. Gêneros orais e escritos na escola. Campinas/SP: Mercado de Letras, 2010, p. 81-108.

DOLZ-MESTRE, J. et al. S'exprimer em français: séquences didactiques pour l'oral et pour l'écrit. Vol. 3, (5e et 6e). Bruxelles: DeBoeck \& Lancier S.A., 2001.

DOLZ, J.; ABOUZAÏD, M. Pluralité des genres et singularité du texte: tensions constitutives de la didactique des langues. Disponível em:

www.forumlecture.ch/www.lesenforum.ch-2/2015 Acesso em: 10 set. 2015.

GERALDI, J. W. O texto na sala de aula. (Org.). São Paulo: Ática, 2006.

GONÇALVES, A.V.; BAZARIM, M. (Orgs.). Interação, gêneros e letramento: a reescrita em foco. São Carlos: Editora Claraluz, 2009.

KOCH, I. V. A coesão textual. São Paulo: Contexto, 1992. Desvendando os segredos do texto. São Paulo: Cortez, 2006.

KOCH, I. V.; TRAVAGLIA, L. C. A coerência textual. São Paulo: Contexto, 2001.

KOCH, V. I.; ELIAS, V. M. Ler e escrever: estratégias de produção textual. São Paulo: Contexto, 2010.

Escrever e argumentar. São Paulo: Contexto, 2016.

MACHADO, A.R. A perspectiva interacionista sociodiscursiva de Bronckart. In: MEURER, J. L. et al. (orgs.) Gêneros: teorias, métodos, debates, 2005, p. 237-259.

MACHADO, A.R.; CRITÓVÃO, V.L.L. A construção de modelos didáticos de gêneros: aportes e questionamentos para o ensino de gêneros. Revista Linguagem em (Dis)curso, v. 6, n.3, p.547-573, set./dez. 2006.MACHADO, A.R.; LOUSADA, E.G. A apropriação de gêneros textuais pelo professor: em direção ao desenvolvimento pessoal e à evolução do "métier". Linguagem em (Dis)curso, Palhoça, SC, v.10, n.3, p.619-633, set./dez. 2010.

MARCUSCHI, L. A. Produção textual, análise de gêneros e compreensão. São Paulo:

Parábola, 2008. 
- Gêneros textuais: definição e funcionalidade. In: DIONÍSIO, A. P.; MACHADO, A.B.; BEZERRA, M.A. (Orgs.). Gêneros textuais \& ensino. Rio de Janeiro: Lucerna, 2010, p. 19-38.

NEIS, I. A. Por uma gramática textual. Letras de Hoje, 44: 35-52, 1981.

NÓVOA, A. Formação de professores e trabalho pedagógico. Lisboa: EDUCA, 2002.

PETITJEAN, A. La transposition didactique en français. Pratiques n. 97/98, juin, 7-34, 1998.

PERRENOUD, Ph. Formar professores em contextos formais em mudança. Prática reflexiva e participação crítica. Universidade de Genebra. Revista Brasileira de Educação, n. 12, p. 5-21, set/dez 1999.

SANTOS, L. W.; TEIXEIRA, C. S. Correção e avaliação de textos. In: COELHO, F. A.; PALOMANES, R. (Orgs.) Ensino de produção textual. São Paulo: Contexto, 2016, p. 2341.

SCHNEUWLY, B. Didactique: construction d'un champ disciplinaire. Education et Didactique, v. 8, n. 1, p. 13-22, 2014.

SCHNEUWLY, B. et al. Les didactiques au centre Formation genevoise des enseignants du secondaire. Revue Suisse des Sciences de l'èducation, 34 (3), Academic Press Fribourg, 2012.

SCHNEUWLY, B. et al. A la recherche de l'objet enseigné: une démarche multifocale. Les Dossiers des sciences de l'éducation, n. 14, p. 77-93, 2005.

SCHNEUWLY, B.; DOLZ, J. et al. Des objets enseignés en classe de français. Le travail de l'enseignant sur la rédaction de textes argumentatifs et sur la subordonnée relative. Presses Universitaires de Rennes, 2009.

Gêneros orais e escritos na escola. São Paulo: Mercado de Letras, 2010.

TRAVAGLIA, L.C. Planejamento de textos para sua produção. In: COELHO, F.A.; PALOMANES, R. Ensino de produção textual, 2016, p. 87-107.

WITTKE, C.I. Ensino de língua materna: PCNs, gramática e discurso. Santa Cruz do Sul: EDUNISC, 2017.

. A produção do texto escrito sob uma perspectiva social. RevLet, v. 04, n. 01, p. 84-98, jan/jul 2012.

Ensino de língua e formação docente. Reflexão teórica e diálogo com professores. Saarbrücken: Editora Verlang. Novas Edições Acadêmicas, 2015.

WITTKE, C.I.; DOLZ, J. Ensino de língua, formação docente e pesquisa: um diálogo com Joaquim Dolz. Fórum Linguístico, v. 12, n. 4, p. 986 - 997, out./dez 2015.

WITTKE, C.I.; SCHNEUWLY, B. A didática na formação do professor de línguas sob a perspectiva do pesquisador Bernard Schneuwly. Calidoscópio, v. 14, n. 2, p. 350-361, mai/ago 2016.

Recebido em 10/03/2018. Aceito em 06/06/2018. 